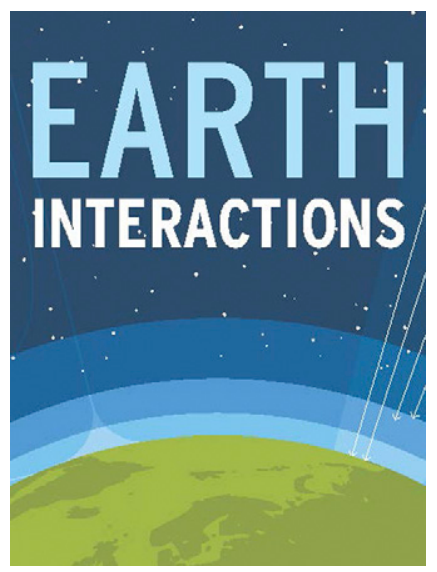

(C) 2017 American Meteorological Society. For information regarding reuse of this content and general copyright information, consult the AMS Copyright Policy (www.ametsoc.org/PUBSReuseLicenses).

\title{
Intercomparison of Model-Estimated Potential Evapotranspiration on the Tibetan Plateau during 1981-2010
}

\section{Lulu Song}

Key Laboratory of Urban Environment and Health, Institute of Urban Environment, Chinese Academy of Sciences, Xiamen, Fujian, China

\section{Qianlai Zhuang}

Department of Earth, Atmospheric and Planetary Sciences, Purdue University, West Lafayette, Indiana

\section{Yunhe Yin and Shaohong Wu}

Key Laboratory of Land Surface Pattern and Simulation, Institute of Geographic Sciences and Natural Resources Research, Chinese Academy of Sciences, Beijing, China

\section{Xudong $\mathbf{Z h u ^ { \mathbf { a } }}$}

Key Laboratory of the Coastal and Wetland Ecosystems (Xiamen University), Ministry of Education, and College of the Environment and Ecology, Xiamen University, and Coastal and Ocean Management Institute, Xiamen University, Xiamen, Fujian, China

Received 26 July 2016; in final form 4 September 2017

\footnotetext{
${ }^{a}$ Corresponding author: Xudong Zhu, xdzhu@xmu.edu.cn
} 
Earth Interactions - Volume 21 (2017) - Paper No. 11 • Page 2

\begin{abstract}
Potential evapotranspiration (PET), the maximum evapotranspiration rate under unlimited water supply, reflects the capacity for transpiration flow and plant primary production. Numerous models have been developed to quantify PET, but there are still large uncertainties in PET estimations. In this study, the authors conducted spatially explicit estimations of daily PET from 1981 to 2010 for eight different land-cover types on the Tibetan Plateau by applying three types of PET models including a combination model (Penman-Monteith), a radiation-based model (Priestley-Taylor), and a temperature-based model (Thornthwaite). This study found that the PET estimated by Thornthwaite model $\left(\mathrm{PET}_{\mathrm{T}}\right)$ was lower than those estimated by Priestley-Taylor $\left(\mathrm{PET}_{\mathrm{PT}}\right)$ and Penman-Monteith models $\left(\mathrm{PET}_{\mathrm{PM}}\right)$. PenmanMonteith model gave the highest estimates of PET on annual and daily scales. The mean annual PET for the whole plateau estimated by these three models varied from 675.1 to $700.5 \mathrm{~mm} \mathrm{yr}^{-1}$, and daily PET varied from 1.33 to $1.92 \mathrm{~mm} \mathrm{day}^{-1}$. The spatial pattern of $\mathrm{PET}_{\mathrm{T}}$ did not agree with the $\mathrm{PET}_{\mathrm{PT}}$ and $\mathrm{PET}_{\mathrm{PM}}$, while the latter two agreed well with each other. Because of different model structures and dominant meteorological drivers, the interannual variability of PET varied significantly among the models. PET $_{\mathrm{PT}}$ and $\mathrm{PET}_{\mathrm{PM}}$ showed a transition around 1993 since the dominant meteorological drivers were different before and after 1993. These disagreements among different models suggested that PET models with different algorithms should be used with caution. This study provided a validation to assist those undertaking PET estimations on the Tibetan Plateau.
\end{abstract}

KEYWORDS: Climate change; Evapotranspiration; Model comparison

\title{
1. Introduction
}

Potential evapotranspiration (PET), a function of available energy, vapor pressure gradient, and vegetation type, indicates an upper limit to water losses by evapotranspiration (Thornthwaite 1948; Penman 1948). In well-watered circumstances, PET can reflect the capacity of ecosystems for transpiration flow and primary production (Fisher et al. 2011). Moreover, as an important input to a variety of aridity indices, drought indices, and climate and hydrologic models (Sentelhas et al. 2010; Currie 1991), PET has drawn increasing attention in the past decades. Different PET models behave disparately, and the simulated PET values greatly affect the results of climate and hydrological models. Therefore, it is important to assess the uncertainties of different PET models.

The choice of PET models depends not only on the important potential controls of the study system but also on what data are available to run the PET model. There are more than 50 PET models varying from temperature-based to radiation-based to physically based process models. Previous studies found that intercomparisons of PET estimates have revealed large uncertainties because of different assumptions and input data involved in PET models. For example, Fisher et al. (2011) compared three different types of PET models and found that the temperature-based model estimated $20 \%-30 \%$ less than the radiation-based and combination models. By contrasting three temperature-based and three radiation-based PET models, Lu et al. (2005) found that PET values were significantly different and greater deviations were found among the temperaturebased models. Moreover, Douglas et al. (2009) demonstrated that annually aggregated Priestley-Taylor $\left(\mathrm{PET}_{\mathrm{PT}}\right)$ and Turc models outperformed the 
Earth Interactions - Volume 21 (2017) • Paper No. 11 • Page 3

Penman-Monteith (PM; PET $\left._{\mathrm{PM}}\right)$ model, and Priestley-Taylor performance appeared to be superior to the other two models on a daily scale. It is therefore important to identify the deviations among PET models, since different PET models give widely inconsistent values at particular locations, as demonstrated in previous studies (Fisher et al. 2005).

This study focuses on the three most commonly used models, and each of them belongs to a different category. The first one is the well-known Penman-Monteith model, which is a combination model taking into consideration energetic drivers (i.e., solar radiation and air temperature) and atmospheric drivers (i.e., vapor pressure deficit and surface wind speed). PET estimates of the Penman-Monteith model are commonly used as the standard values and adopted to evaluate other PET models (Lu et al. 2005). However, the main drawback of the PenmanMonteith model is its strict inputs. The second category is the temperaturebased models, which are widely used because of their simple structures, especially when only temperature data are available (Xu and Singh 2001). The Thornthwaite (1948) model, a typical temperature-based model, has one particular advantage for ecological application-the inclusion of daylight hours, which are implicitly related to radiation and the relative ability to photosynthesize (Fisher et al. 2011). Another simpler, but effective, PET model was developed by Priestley and Taylor (1972) for a well-watered surface by introducing a unitless constant to the Penman equation. The Priestley-Taylor model has been recognized as one of the most popular radiation-based models ( $\mathrm{Xu}$ and Singh 2000).

The Tibetan Plateau, which is rich in lakes, rivers, glaciers, and wetlands, is an ideal area for investigating the interactions between hydrological cycles and climatic change because the ecosystems remain relatively undisturbed and the South Asian Monsoon develops wide ranges of temperature and moisture gradients across the plateau ( $\mathrm{Li}$ and Fang 1999). The spatial and temporal variability of PET on the Tibetan Plateau have especially been of concern in climatological and hydrological studies in recent decades. However, most of the previous studies were conducted by adopting the Penman-Monteith model to estimate PET and identify the dominant meteorological factors that drive PET on the Tibetan Plateau (Zhang et al. 2009; Chen et al. 2006; Wang et al. 2013; Liang et al. 2013; Yin et al. 2010). Because of inaccessibility, the complex terrain, sparse meteorological stations, and high elevation $(>4500 \mathrm{~m})$ of the Tibetan Plateau, not all meteorological variables required by the PenmanMonteith model are completely observed in some regions. The applicability of alternative PET models has not yet been assessed on the Tibetan Plateau. Therefore, it is necessary to assess the uncertainties associated with alternative PET models, especially when the meteorological data are incompletely observed.

In this study, we extend previous studies by 1) comparing the performance of three PET models on daily, seasonal, and annual scales; 2) assessing the differences in PET values for different land-cover types on the Tibetan Plateau during 19812010 ; 3) investigating the dominant meteorological variables that determine the interannual variability of PET; and 4) providing a validation for choosing a PET model for use on the Tibetan Plateau. 
Earth Interactions - Volume 21 (2017) • Paper No. 11 • Page 4

\section{Materials and methods}

\subsection{Study site}

The Tibetan Plateau $\left(25^{\circ}-40^{\circ} \mathrm{N}, 75^{\circ}-105^{\circ} \mathrm{E}\right)$, the highest (average elevation $>$ $4000 \mathrm{~m})$ and largest $\left(>2.5\right.$ million $\mathrm{km}^{2}$ ) highland in the world, is located in western China. Most areas of the plateau are characterized with an arid-semiarid climate. The mean annual precipitation is $473 \mathrm{~mm}$, ranging from 50 to $1000 \mathrm{~mm}$. The mean annual temperature is $3.8^{\circ} \mathrm{C}$, ranging from $-15^{\circ}$ to $10^{\circ} \mathrm{C}$. The spatial patterns of precipitation and temperature result in an increase in aridity from southeast to northwest of the Tibetan Plateau. More than $60 \%$ of the plateau is alpine grasslands, which includes alpine meadows, alpine steppes, and alpine desert.

\subsection{Data sources}

High-quality daily in situ meteorological datasets from 1981 to 2010 , including maximum air temperature $T_{\max }\left({ }^{\circ} \mathrm{C}\right)$, minimum air temperature $T_{\min }\left({ }^{\circ} \mathrm{C}\right)$, relative humidity RH (\%), wind speed at 10-m height $U\left(\mathrm{~m} \mathrm{~s}^{-1}\right)$, sunshine duration $S(\mathrm{~h})$, and precipitation $P(\mathrm{~mm})$ from 80 out of 109 meteorological stations (all 80 meteorological stations are built before 1981, the locations never change during the study period, and the stations have more than $95 \%$ of the recorded data) over the Tibetan Plateau were downloaded from China Meteorological Administration (CMA) website (http://data.cma.cn/site/index.html). The altitudes of all 80 stations varied between 505 and $4670 \mathrm{~m}$. Station density in high-altitude regions (western of plateau) is much more sparse than in the lowlands (eastern of plateau; e.g., only two stations are available in the west; Figure 1). Missing data were estimated from average values of other years observed at the same station. The 80 sites covered a variety of land-cover types: needleleaf forest (5), broadleaf forest (1), shrub (10), desert (3), alpine steppe (16), alpine meadow (19), alpine cushion vegetation (22), and others (4). Annual, seasonal, and monthly average values of PET were calculated from the daily values.

\subsection{Calculation of PET}

\subsubsection{Penman-Monteith model}

The Penman-Monteith model (Penman 1948; Monteith 1965) is a physically based method that is widely used for PET estimation. In 1998, the Food and Agricultural Organization (FAO) modified the Penman-Monteith model by defining a hypothetical reference grass with an assumed height of $0.12 \mathrm{~m}$, a fixed surface resistance of $70 \mathrm{~s} \mathrm{~m}^{-1}$, and an albedo of 0.23 . The assumptions can be applied to the Tibetan Plateau, where more than $60 \%$ is alpine grasslands (Song et al. 2017). The Penman-Monteith model is expressed as (Allen et al. 1998)

$$
\mathrm{PET}_{\mathrm{PM}}=\frac{0.408 \Delta\left(R_{n}-G\right)+\gamma[900 /(T+273)] U_{2}\left(e_{s}-e_{a}\right)}{\Delta+\gamma\left(1+0.34 U_{2}\right)},
$$

where $\mathrm{PET}_{\mathrm{PM}}$ is the potential evapotranspiration $\left(\mathrm{mm} \mathrm{day}^{-1}\right), \Delta$ is the slope of the saturated vapor pressure curve $\left(\mathrm{kPa}^{\circ} \mathrm{C}^{-1}\right), R_{n}$ is the net radiation $\left(\mathrm{MJ} \mathrm{m}^{-2}\right.$ day $\left.^{-1}\right), G$ is 


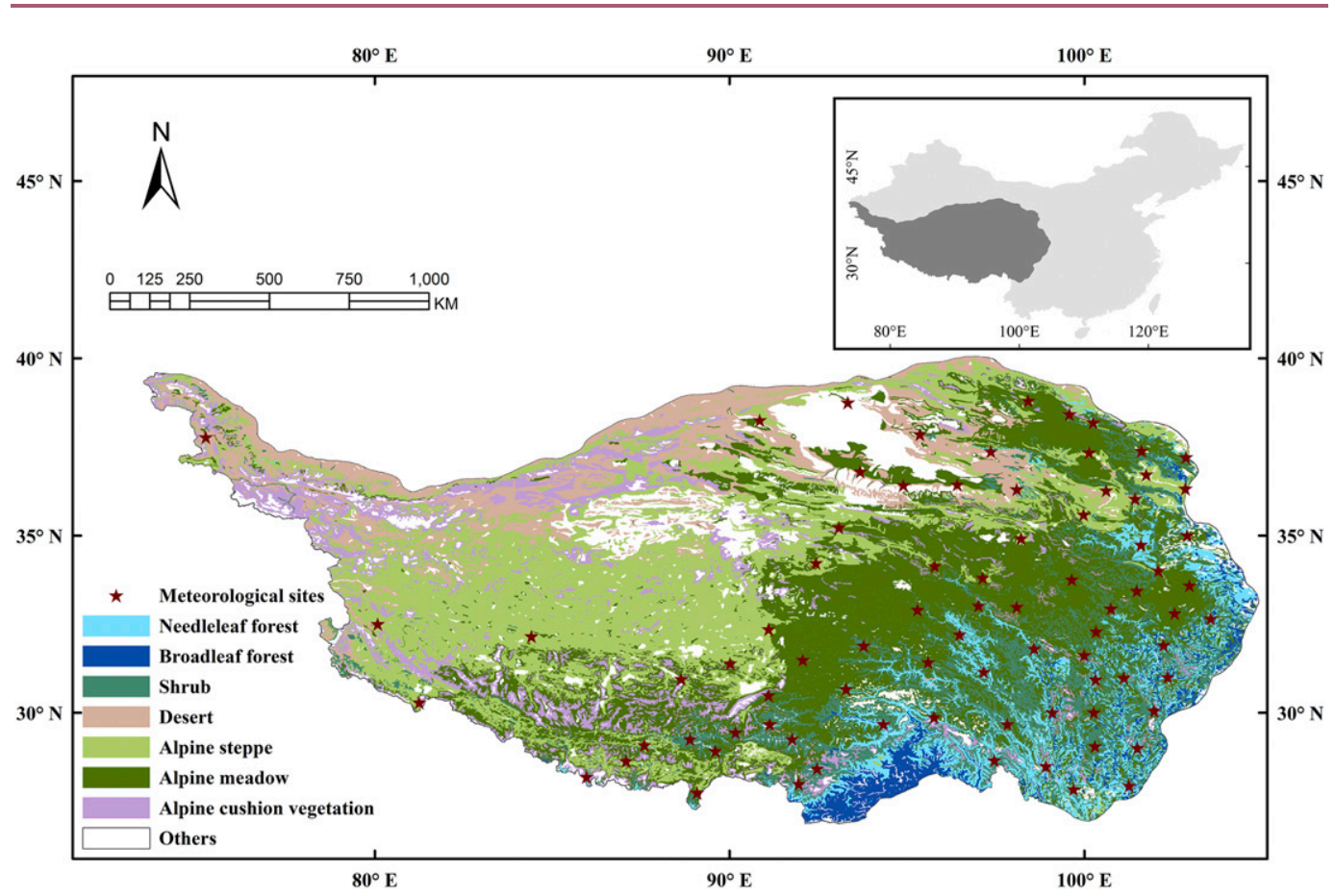

Figure 1. Location of meteorological stations and distribution of land-cover types on the Tibetan Plateau.

the soil heat flux density $\left(\mathrm{MJ} \mathrm{m}^{-2} \mathrm{day}^{-1}\right), e_{s}$ is the saturation vapor pressure $(\mathrm{kPa})$, $e_{a}$ is the actual vapor pressure $(\mathrm{kPa}),\left(e_{s}-e_{a}\right)$ is the saturation vapor pressure deficit (VPD; $\mathrm{kPa}$ ) at temperature $T, \gamma$ is the psychrometric constant $\left(\mathrm{kPa}^{\circ} \mathrm{C}^{-1}\right)$, and $U_{2}$ is the wind speed at 2-m height $\left(\mathrm{m} \mathrm{s}^{-1}\right)$. A full description of the PenmanMonteith model is available in appendix A.

\subsubsection{Priestley-Taylor model}

The Priestley-Taylor equation (Priestley and Taylor 1972) is a simplification of the original Penman method, where the aerodynamic term is replaced by an empirical coefficient, known as the Priestley-Taylor parameter $\alpha$. The model takes the following form:

$$
\mathrm{PET}_{\mathrm{PT}}=\alpha \frac{\Delta}{\Delta+\gamma}\left(\frac{R_{n}-G}{\lambda}\right),
$$

where $\lambda$ is the latent heat of vaporization ( $\mathrm{MJ} \mathrm{kg}^{-1}$ ), and $\alpha$ is an empirical constant. The terms $R_{n}, G, \Delta$, and $\gamma$ are as defined for the Penman-Monteith model.

Instead of setting $\alpha$ as an empirical constant ( $\alpha=1.26$ ), we calculated $\alpha$ using the equation recommended by Er-Raki et al. (2010), since previous studies have shown that the appropriate value for the parameter $\alpha$ varied considerably from humid to arid regions. For example, McNaughton and Black (1973) suggested 


\section{Earth Interactions - Volume 21 (2017) • Paper No. 11 • Page 6}

that $\alpha$ should be 1.05 in a humid region. However, the value of 1.74 had been suggested for an arid region by Steiner et al. (1991). The $\alpha$ equation in Er-Raki et al. (2010) was calibrated by minimizing the RMSE between the PET computed by Priestley-Taylor model and FAO-PM model in a semiarid region. Er-Raki et al. (2010) concluded that the calibration of $\alpha$ could be applied in many areas (arid, humid):

$$
\alpha=-0.014 \mathrm{RH}+2.33 \text {. }
$$

It is noted that $\alpha$ can vary from 0.93 to 2.33 , depending on the climatic conditions.

\subsubsection{Thornthwaite model}

The PET in the Thornthwaite model ( $\mathrm{PET}_{\mathrm{T}}$; Thornthwaite 1948) is a function of the mean air temperature $T_{\text {mean }}\left({ }^{\circ} \mathrm{C}\right)$, climatological normal annual temperature $T_{n}$, and photoperiod (maximum number of sunshine duration $S$ ):

$$
\begin{aligned}
& \operatorname{PET}_{\mathrm{T}}= \begin{cases}0, & T_{\text {mean }}<0^{\circ} \mathrm{C} \\
16\left(10 \frac{T_{\text {mean }}}{I}\right)^{\alpha}, & 0^{\circ} \mathrm{C} \leq T_{\text {mean }} \leq 26^{\circ} \mathrm{C} \quad \text { and } \\
-415.85+32.24 T_{\text {mean }}-0.43 T_{\text {mean }}^{2}, & T_{\text {mean }}>26^{\circ} \mathrm{C}\end{cases} \\
& T_{\text {mean }}=\frac{1}{2}\left(T_{\text {max }}+T_{\text {min }}\right),
\end{aligned}
$$

where $\mathrm{PET}_{\mathrm{T}}$ is the standard, 30-day evapotranspiration [mm (30 day $)^{-1}$, considering $S=12 \mathrm{~h}$; and $I$ and $\alpha$ are thermal indices, calculated by

$$
\begin{aligned}
I & =\sum_{n=1}^{12}\left(0.2 T_{n}\right)^{1.514}, \quad T_{n}>0, \quad \text { and } \\
\alpha & =6.75 \times 10^{-7} I^{3}-7.71 \times 10^{-5} I^{2}+1.79 \times 10^{-2} I+0.49 .
\end{aligned}
$$

Finally, PET $_{\mathrm{T}, \mathrm{day}}$, in millimeters per day, is estimated by the following expression:

$$
\mathrm{PET}_{\mathrm{T}, \mathrm{day}}=\frac{\mathrm{PET}_{\mathrm{T}}}{30} \times \frac{S}{12} .
$$

To adjust the original Thornthwaite model to arid and very humid conditions, Camargo et al. (1999) replaced the $T_{\text {mean }}$ by the effective temperature $T_{\text {ef }}$, which is used in this study: 


$$
\begin{gathered}
\text { Earth Interactions } ・ \text { Volume } 21(2017) \cdot \text { Paper No. } 11 \cdot \text { Page } 7 \\
\qquad T_{\mathrm{ef}}=\frac{1}{2} k\left(3 T_{\max }-T_{\min }\right), \quad k=0.69 .
\end{gathered}
$$

\subsection{Spatiotemporal analyses of PET}

\subsubsection{Spatial interpolation}

To study the spatial distribution pattern of PET, the spatial interpolation from the annual- and seasonal-scale PET was performed using the inverse-distanceweighted (IDW) method, which is a commonly accepted method in climatic and meteorological research (Lu and Wong 2008; Song et al. 2017).

\subsubsection{Trend analyses}

To detect the magnitude of the overall trends in meteorological factors and PET, the linear regression method was used, which is the most frequently used method for quantifying long-term trends in hydroclimatic variables (Wang et al. 2013).

The significance of a trend was assessed by the Mann-Kendall test (Mann 1945; Kendall 1975), which is a nonparametric method used commonly for time series (Sneyers 1990). The Mann-Kendall test is popular because it is distribution free, robust against outliers, and has a higher power-to-test tendency than many other commonly used tests. The equation below is used to estimate whether a series has a significant trend:

$$
\begin{aligned}
M & =\tau / \sigma_{\tau} \\
\tau & =\frac{4 V}{N(N-1)}-1 \\
\sigma_{\tau}^{2} & =\frac{2(2 N+5)}{9 N(N-1)},
\end{aligned}
$$

where $N$ is the series length and $V$ is the number of the dual observed values in a series. In this study, $p<0.05$ is regarded as a significant trend. A positive $M$ indicates an ascending trend and vice versa. If a series has a significant trend, $|M|>M_{p / 2}=1.96$.

The segmented regression, which simultaneously detects both shift trends and step changes (Shao and Campbell 2002; Shao et al. 2010) as compared with other detection regression, was employed to investigate the segmented change patterns in meteorological and PET variables. All the statistical analyses involved in this paper were implemented with MATLAB 10.0.

\section{Results}

\subsection{Performance of different PET models at mean annual scales}

At an annual time scale, PET estimated by three models are all very similar: the PET $_{\mathrm{PM}}$ and $\mathrm{PET}_{\mathrm{PT}}$ differ by only $7.2 \mathrm{~mm}$, and $\mathrm{PET}_{\mathrm{T}}$ and $\mathrm{PET}_{\mathrm{PM}}$ differ by $25.5 \mathrm{~mm}$. 
However, there is large spatial variability of PET (Figure 2). Specifically, a west-toeast declining gradient of mean annual PET is obvious for both PET $_{\mathrm{PM}}$ and $\mathrm{PET}_{\mathrm{PT}}$ estimates. The mean annual PET $\mathrm{PM}_{\mathrm{PM}}$ is $700.5 \pm 143.2 \mathrm{~mm}$ (ranging from 474.0 to $1112.5 \mathrm{~mm}$ ) followed by PET $_{\mathrm{PT}}$, which provides a lower mean annual PET of 693.3 $\pm 108.8 \mathrm{~mm}$ (ranging from 505.7 to $1052.1 \mathrm{~mm}$ ). The mean annual $\mathrm{PET}_{\mathrm{T}}(675.1 \pm$ $98.4 \mathrm{~mm} \mathrm{yr}^{-1}$ ) is slightly lower than those calculated by the other two models, with its lowest value of $477.4 \mathrm{~mm} \mathrm{yr}^{-1}$ in the middle of the Tibetan Plateau and highest value of $1004.3 \mathrm{~mm} \mathrm{yr}^{-1}$ in the southeast.

From spring to autumn, the spatial distribution of PET values estimated by different models is similar to that of mean annual PET (Figure 3). For the whole region, the maximum PET occurs in summer with values ranging from $252.7 \pm$ $36.3\left(\mathrm{PET}_{\mathrm{T}}\right)$ to $308.3 \pm 58.5 \mathrm{~mm}\left(\mathrm{PET}_{\mathrm{PT}}\right)$. The minimum PET occurs in winter with values ranging from $35.8 \pm 20.2\left(\mathrm{PET}_{\mathrm{PT}}\right)$ to $80.3 \pm 32.2 \mathrm{~mm}\left(\mathrm{PET}_{\mathrm{T}}\right)$. Our results show that the standard deviations are largest in summer and smallest in winter.

At site levels, the temporal changes of annual PET show a mixed pattern of both upward and downward trends for different parts of the Tibetan Plateau from 1981 to 2010 (Figure 4b). At an annual scale, increasing trends in annual PET are observed for $43 \%$ of all meteorological stations with $\mathrm{PET}_{\mathrm{PM}}, 69 \%$ with $\mathrm{PET}_{\mathrm{PT}}$, and 95\% with $\mathrm{PET}_{\mathrm{T}}$, wherein annual PET shows significant changing trends $(p<0.05)$ at $18 \%, 23 \%$, and $80 \%$ of all stations, corresponding to $\mathrm{PET}_{\mathrm{PM}}, \mathrm{PET}_{\mathrm{PT}}$, and $\mathrm{PET}_{\mathrm{T}}$, respectively. The stations with significant negative trends estimated by $\mathrm{PET}_{\mathrm{PM}}$ are mainly distributed at the northern, southwestern, and southeastern corners of the plateau. Significant increases in annual PET $_{\mathrm{PM}}$ mainly occur east of the plateau. Similar to $\mathrm{PET}_{\mathrm{PM}}$, the stations with significant increasing trends of $\mathrm{PET}_{\mathrm{PT}}$ are mainly distributed in the eastern plateau.

Meanwhile, Figure 4a illustrates the interannual trends of PET for the entire plateau. It shows that the plateau is characterized with the different interannual trends by different models. First, the interannual PET $\mathrm{PM}_{\mathrm{PM}}$ and $\mathrm{PET}_{\mathrm{PT}}$ trends both have a transition period, in which PET decreases from 1981 through 1993 and reverses after 1994. Specifically, PET $_{\mathrm{PM}}$ has decreased by $3.4 \mathrm{~mm} \mathrm{yr}^{-1}(p<0.05)$ during 1981-93, while PET $_{\mathrm{PM}}$ has increased by $2.3 \mathrm{~mm} \mathrm{yr}^{-1}(p<0.1)$ since 1994. PET $_{\mathrm{PT}}$ decreases significantly $(p<0.05)$ by $2.0 \mathrm{~mm} \mathrm{yr}^{-1}$ and increases insignificantly by $1.0 \mathrm{~mm} \mathrm{yr}^{-1}$. Second, as opposed to the results estimated by the other two models, $\mathrm{PET}_{\mathrm{T}}$ demonstrates a slightly increasing trend $\left(0.5 \mathrm{~mm} \mathrm{yr}^{-1}\right.$, $p=0.9)$ before 1993 and shows a strong increasing trend after $1994\left(1.9 \mathrm{~mm} \mathrm{yr}^{-1}\right.$, $p<0.01)$.

\subsection{Performance of different PET models at daily time scales}

The PET values estimated by the three models show a strong seasonality: mean daily PET averaged over 80 stations gradually increases from spring to summer and then decreases from autumn to winter (Figure 5). The $\mathrm{PET}_{\mathrm{PM}}$ ranges from $0.60 \pm$ $0.12 \mathrm{~mm}_{\text {day }}{ }^{-1}$ in winter to $3.21 \pm 0.42 \mathrm{~mm}$ day $^{-1}$ in summer with a mean daily $\mathrm{PET}_{\mathrm{PM}}$ of $1.92 \pm 0.28 \mathrm{~mm}$. The long-term, annual-mean, daily $\mathrm{PET}_{\mathrm{PT}}$ is $1.90 \pm$ $0.30 \mathrm{~mm}$ day $^{-1}$ with an annual maximum of $3.78 \pm 0.62 \mathrm{~mm}^{-1 a y}{ }^{-1}$ and minimum of $0.16 \pm 0.02 \mathrm{~mm}^{-1}{ }^{-1}$. When compared with $\mathrm{PET}_{\mathrm{PM}}$ and $\mathrm{PET}_{\mathrm{PT}}, \mathrm{PET}_{\mathrm{T}}$ has the 
Earth Interactions - Volume 21 (2017) • Paper No. 11 • Page 9

(a)

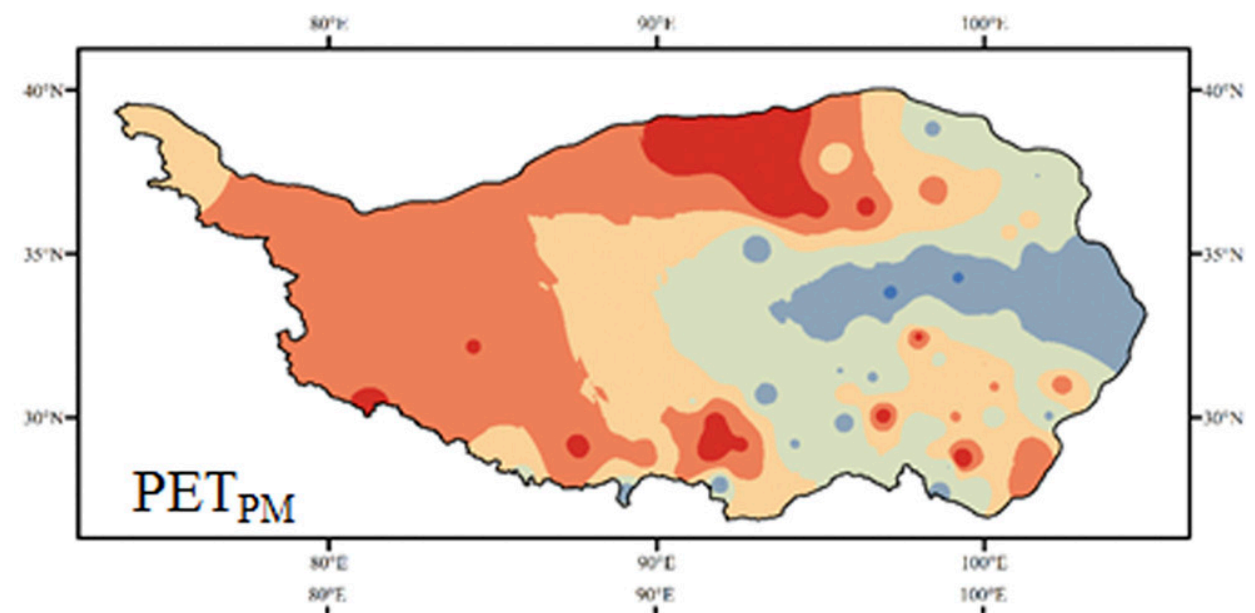

(b)

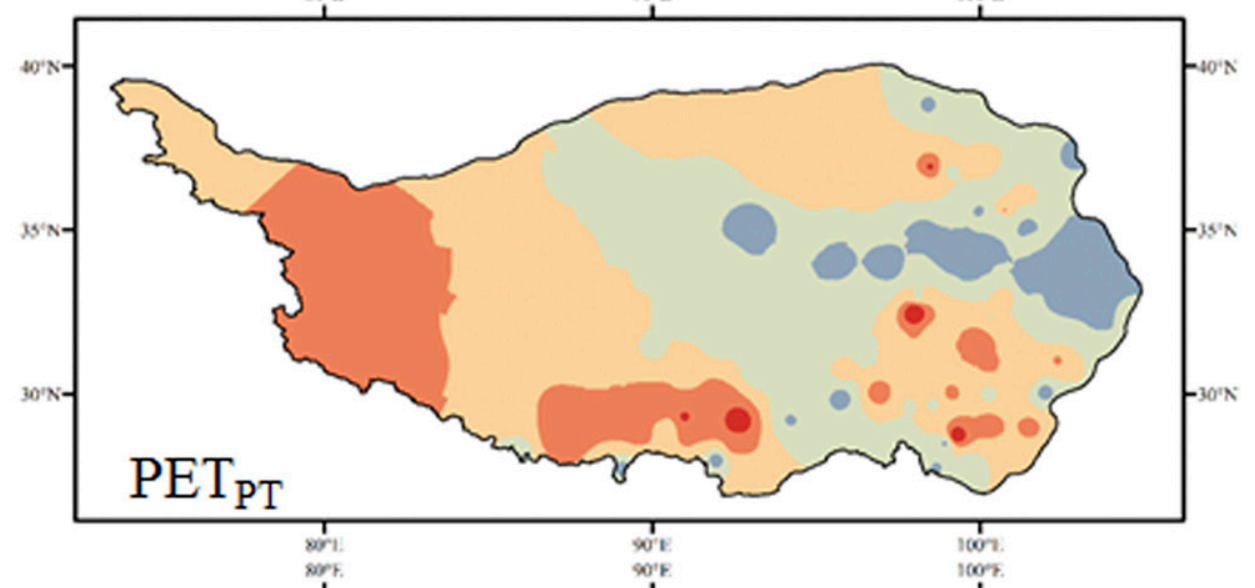

(c)

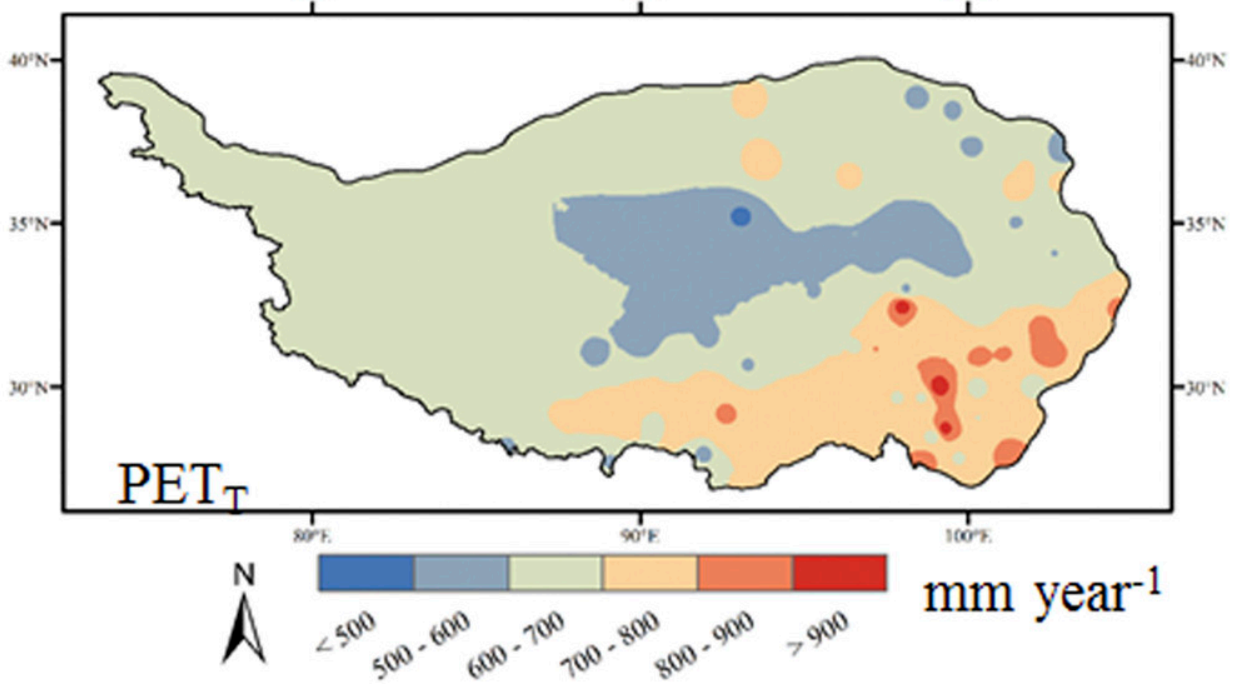

Figure 2. Comparison of spatial distribution of mean annual PET on the Tibetan Plateau from 1981 to 2010 determined by three models. 


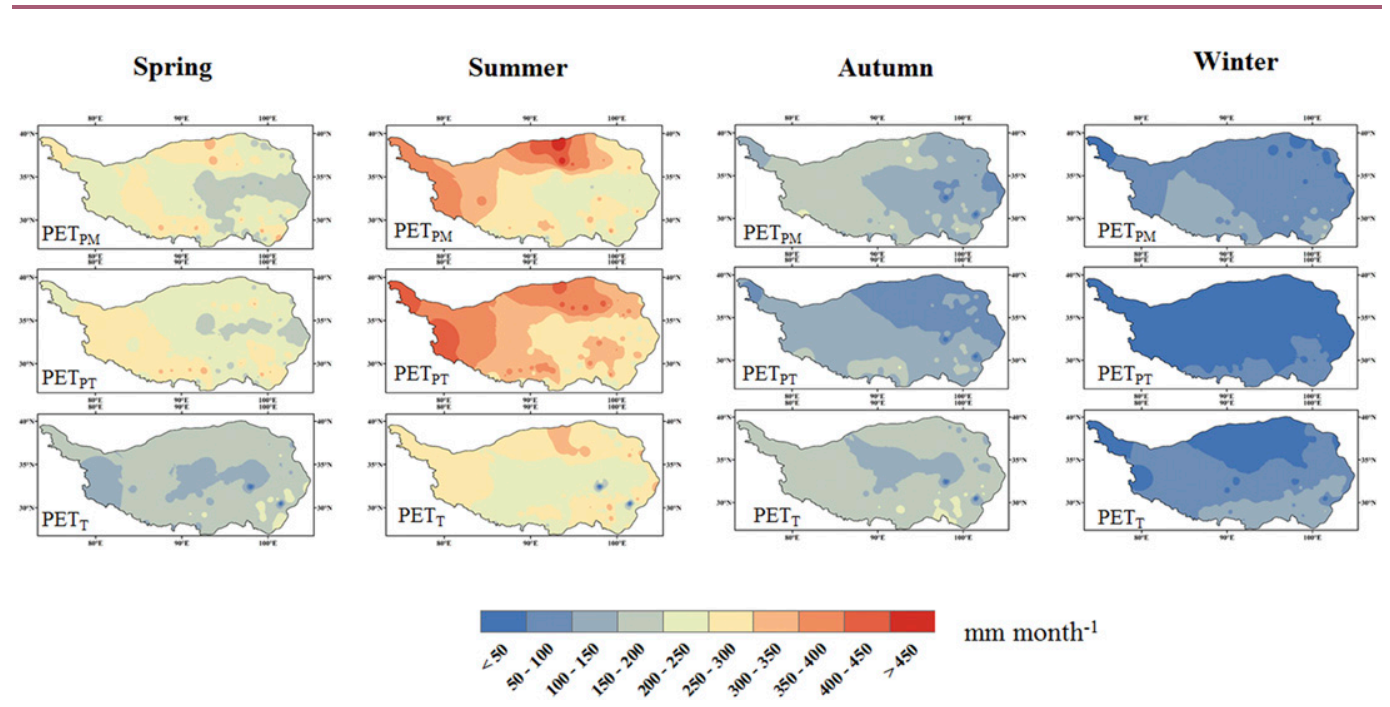

Figure 3. Comparison of spatial distribution of mean seasonal PET on the Tibetan Plateau from 1981 to 2010 determined by three models.

lowest value. From 1981 to $2010, \mathrm{PET}_{\mathrm{T}}$ ranges from $0.45 \pm 0.15$ to $2.89 \pm$ $3.17 \mathrm{~mm} \mathrm{day}^{-1}$ with a mean daily value of $1.33 \pm 0.97 \mathrm{~mm} \mathrm{day}^{-1}$.

With respect to the 1:1 line (where the results from the two models would equal each other), the $\mathrm{PET}_{\mathrm{PT}}$ provides the best agreement with $\mathrm{PET}_{\mathrm{PM}}$ (Figure 6). The coefficient of determination $\left(R^{2}=0.98, p<0.001\right)$ and the slope are close to 1 ,

(a)
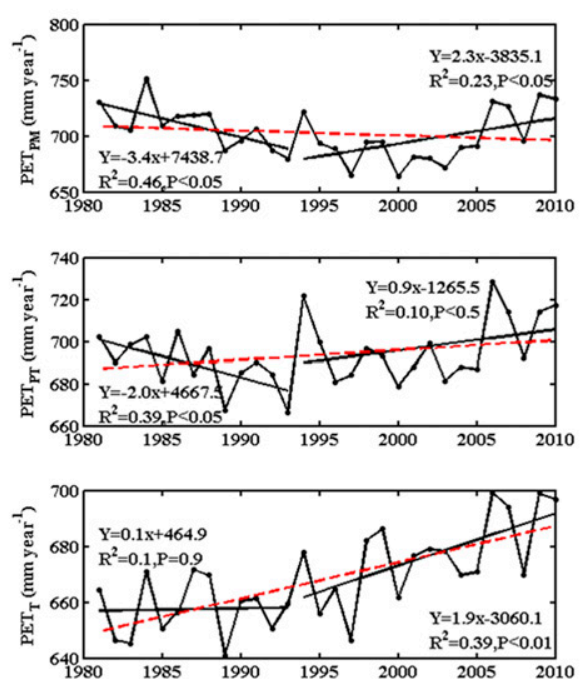

(b)
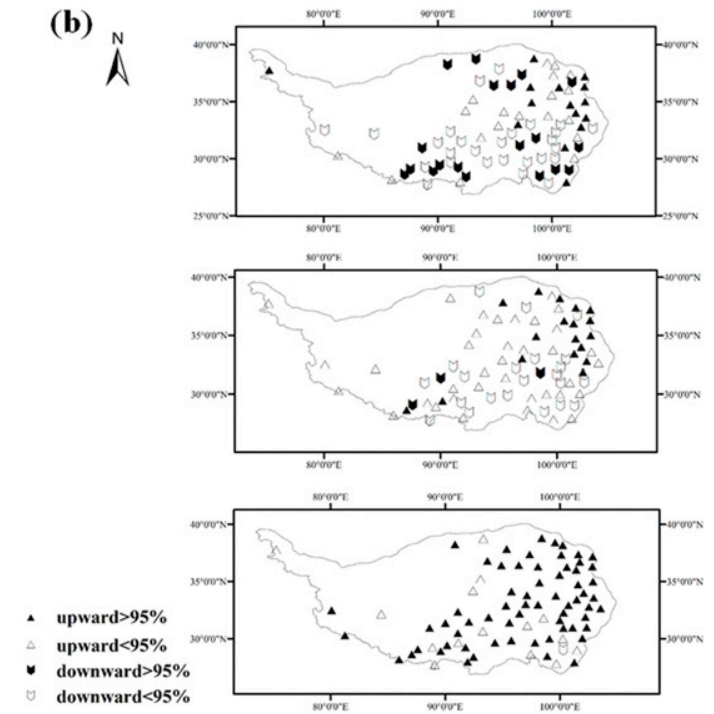

Figure 4. Interannual changes of PET for meteorological stations and the entire Tibetan Plateau from 1981 to 2010 estimated by three models. 

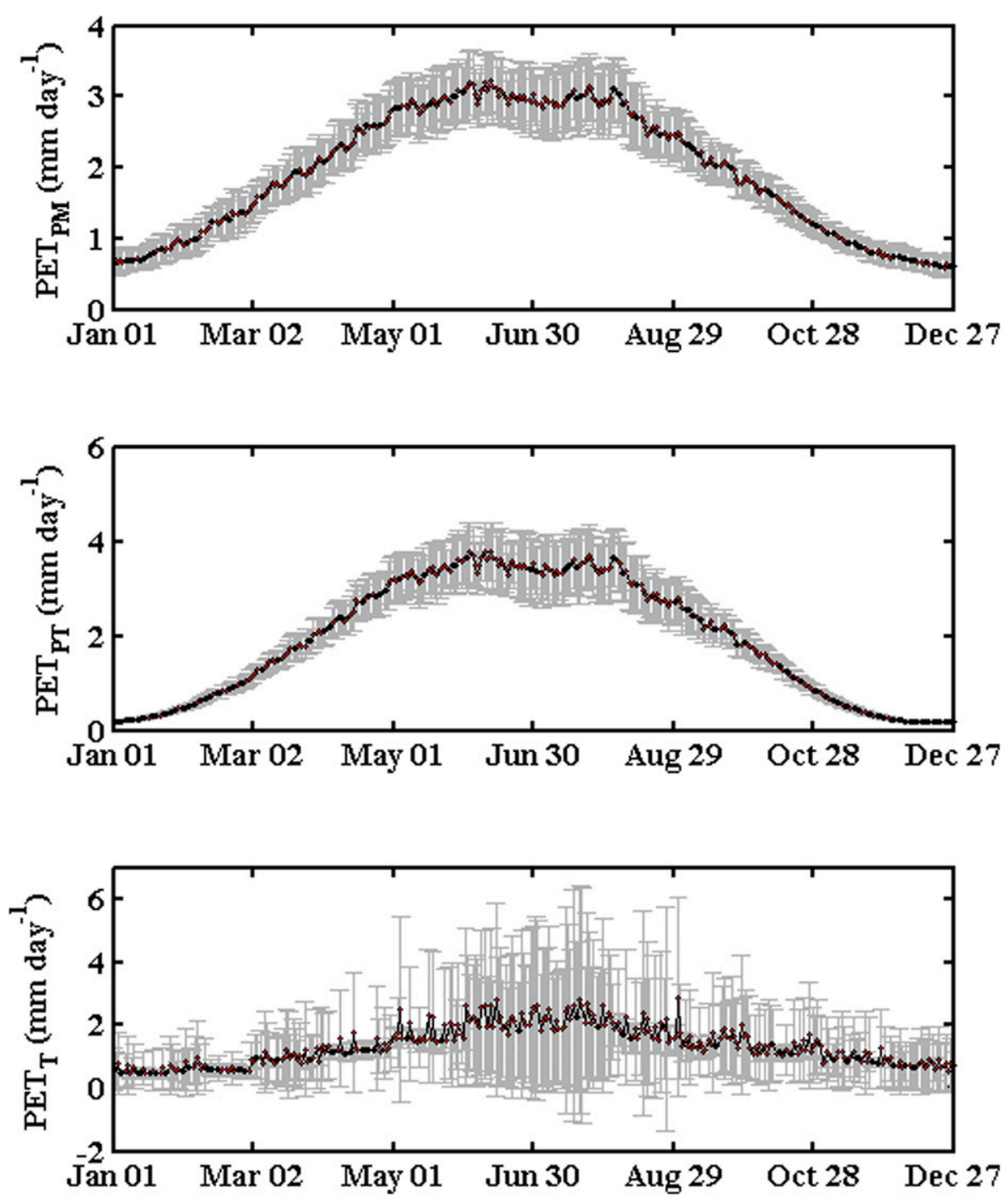

Figure 5. Average seasonal distribution of daily PET on the Tibetan Plateau calculated by three models. Each data point represents an average of 30 daily PET values obtained from 1981 to 2010 . Vertical bars indicate the standard deviation of PET for a given day.

with acceptable RMSE of $0.12 \mathrm{~mm}^{-1 a y}{ }^{-1}$. When compared with $\mathrm{PET}_{\mathrm{PM}}, \mathrm{PET}_{\mathrm{T}}$ performs less well with $R^{2}$ of $0.80(p<0.001)$ and RMSE of $0.3 \mathrm{~mm}^{2}$ day $^{-1}$.

\subsection{PET for different land-cover types}

Our results show that, for eight land-cover types, the three PET models perform similarly for the majority of land-cover types but diverge greatly for some landcover types (Figure 7). For example, $\mathrm{PET}_{\mathrm{PM}}$ and $\mathrm{PET}_{\mathrm{PT}}$ differ by only $0.3 \%$ at shrub sites and $0.4 \%$ at broadleaf forest sites. $\mathrm{PET}_{\mathrm{T}}$ for desert and alpine steppe are 
Earth Interactions - Volume 21 (2017) • Paper No. 11 • Page 12

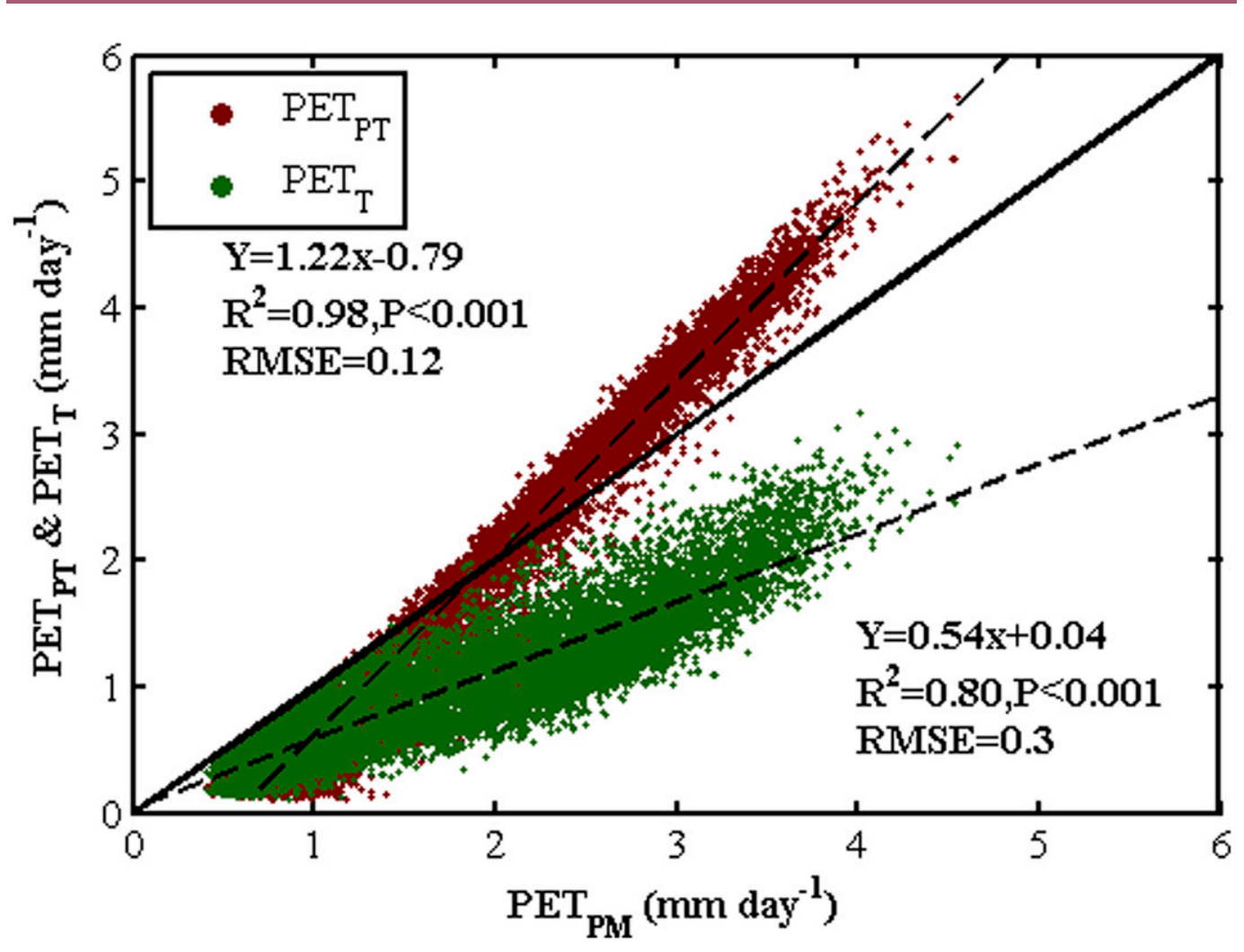

Figure 6. Comparisons of daily PET estimates derived from three models.

lower than $\mathrm{PET}_{\mathrm{PM}}$ by $11 \%$ and $12 \%$. However, $\mathrm{PET}_{\mathrm{T}}$ for broadleaf forest is higher than $\mathrm{PET}_{\mathrm{PT}}$ and $\mathrm{PET}_{\mathrm{PM}}$ by $18 \%$. Furthermore, the results of these model estimations indicate that the broadleaf forest has the highest PET varying from 817.2 to $1004.3 \mathrm{~mm} \mathrm{yr}^{-1}$, while alpine meadow has the lowest PET, ranging from 589.2 to $648.5 \mathrm{~mm} \mathrm{yr}^{-1}$.

Interannual variabilities of PET for different land-cover types are different among the three models (Table 1). For example, $\mathrm{PET}_{\mathrm{T}}$ for all land-cover types significantly increased for the last 30 years, and the largest increase is found in broadleaf forest $\left(2.79 \mathrm{~mm} \mathrm{yr}^{-1}\right)$. However, most land-cover types show decreasing trends in $\mathrm{PET}_{\mathrm{PM}}$. Only desert, alpine steppe, and "others" show increases in PET $_{\mathrm{PM}}$ with the trends ranging from 0.38 to $2.66 \mathrm{~mm} \mathrm{yr}^{-1}$. Similar with $\mathrm{PET}_{\mathrm{T}}$, six of the eight land-cover types demonstrate slightly increasing patterns during 1981-2010 in PET $_{\mathrm{PT}}$.

\subsection{Differences in meteorological regulations of the PET models}

The meteorological factors, which control temporal variations of PET, include dynamic factors such as wind speed $U$; thermodynamic factors such as temperature $T_{\text {mean }}$, radiation $R_{n}$, and sunshine duration $S$; and water factors such as precipitation $P$ and relative humidity RH (Q. Liu et al. 2010). The interannual trends of meteorological factors are investigated to explain the detected PET trends (Figure 8). 


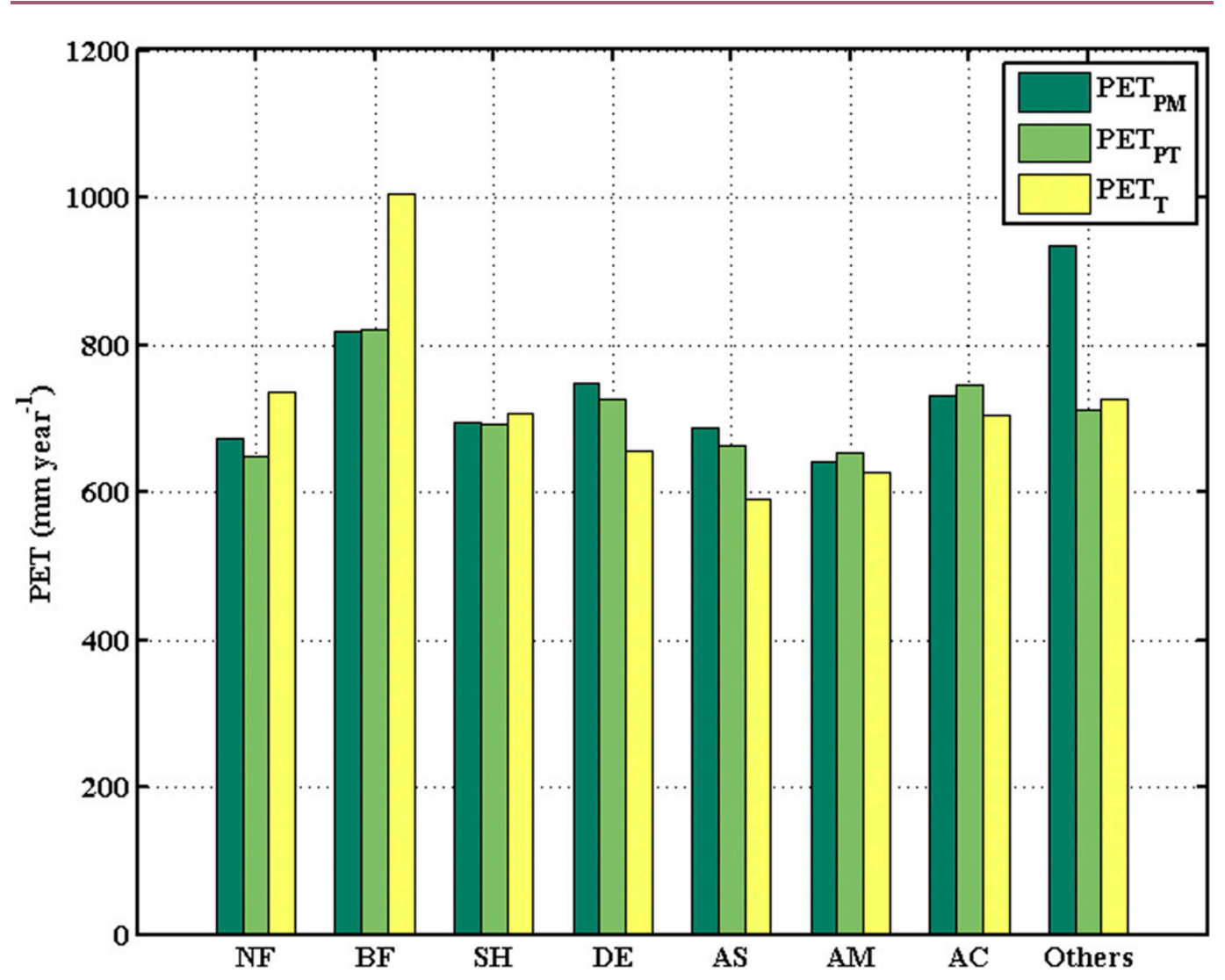

Figure 7. Mean annual PET estimates for land-cover types on the Tibetan Plateau derived from three models (land-cover types: needleleaf forest (NF), broadleaf forest (BF), shrub (SH), desert (DE), alpine steppe (AS), alpine meadow (AM), and alpine cushion vegetation (AC)).

The results show that $R_{n}\left(R^{2}=0.20, p<0.05\right)$, RH $\left(R^{2}=0.12, p<0.1\right), U\left(R^{2}=\right.$ $0.81, p<0.001)$, and $S\left(R^{2}=0.25, p<0.05\right)$ decrease as a whole during 19812010. Nevertheless, $T_{\text {mean }}\left(R^{2}=0.76, p<0.001\right)$ and $P\left(R^{2}=0.25, p<0.05\right)$ increase from 1981 to 2010 . Moreover, according to the temporal variation patterns of PET, we divide the trends of meteorological factors into two stages. Although there are the same increasing or decreasing trends in $R_{n}, T_{\text {mean }}, U, S$, and $P$ between two stages, the slopes of trends are totally different. For example, $U$ decreases at a rate of $0.02 \mathrm{~m} \mathrm{~s}^{-1} \mathrm{yr}^{-1}$ during the first period (1981-93) and then decreases at a rate of $0.004 \mathrm{~m} \mathrm{~s}^{-1} \mathrm{yr}^{-1}$ during the second period (1994-2010). Different from other meteorological factors, a slightly increasing trend in $\mathrm{RH}\left(R^{2}=0.10, p=0.3\right)$ is found during the period of 1981-93, while an obvious decreasing trend $\left(R^{2}=\right.$ $0.62, p<0.001$ ) can be found during the period of 1994-2010.

To identify the controlling meteorological factors driving interannual variations of PET and the relative contributions of different factors, we explore the correlations between PET and meteorological factors. The correlation analyses are conducted for two periods (Table 2). The results illustrate that the decreasing $U\left(R^{2}=0.72\right.$, $p<0.01)$ is most correlated with the decrease of $\mathrm{PET}_{\mathrm{PM}}$ during 1981-93. 
Earth Interactions • Volume 21 (2017) • Paper No. 11 • Page 14

Table 1. Correlation coefficients squared (coefficient of determination; $R^{2}$ ) and slope $b$ of the linear trend of annual PET for land-cover types on the Tibetan Plateau during the period 1981-2010 calculated by three models.

\begin{tabular}{|c|c|c|c|c|c|c|}
\hline \multirow[b]{2}{*}{ Land-cover types } & \multicolumn{2}{|c|}{$\mathrm{PET}_{\mathrm{PM}}$} & \multicolumn{2}{|c|}{$\mathrm{PET}_{\mathrm{PT}}$} & \multicolumn{2}{|c|}{$\mathrm{PET}_{\mathrm{T}}$} \\
\hline & $R^{2}$ & $b$ & $R^{2}$ & $b$ & $R^{2}$ & $b$ \\
\hline Needleleaf forest & 0.14 & $-1.59 *$ & $<0.01$ & -0.11 & 0.34 & $1.21 * * *$ \\
\hline Broadleaf forest & 0.04 & -0.14 & 0.01 & 0.29 & 0.20 & $2.79 *$ \\
\hline Shrub & 0.14 & $-1.70 *$ & $<0.01$ & -0.08 & 0.38 & $1.37 * * *$ \\
\hline Desert & 0.34 & $2.06 * * *$ & 0.27 & $1.39 * *$ & 0.38 & $1.20 * * *$ \\
\hline Alpine steppe & 0.02 & 0.38 & 0.17 & $0.75^{*}$ & 0.42 & $1.15 * * *$ \\
\hline Alpine meadow & $<0.01$ & -0.05 & 0.06 & 0.45 & 0.36 & $1.07 * * *$ \\
\hline Alpine cushion vegetation & 0.11 & -0.83 & 0.08 & 0.51 & 0.54 & $1.40 * * *$ \\
\hline Others & 0.35 & $2.66 * * *$ & 0.06 & 0.45 & 0.68 & $2.03 * * *$ \\
\hline
\end{tabular}

Asterisks represent the significant level ( $p$ ) of the trend according to the linear regression: $*=p \leq 0.05, * *=p \leq$ 0.01 , and $* * *=p \leq 0.001$.

However, the most dominating factor for the increasing $\mathrm{PET}_{\mathrm{PM}}$ is $\mathrm{RH}\left(R^{2}=0.73\right.$, $p<0.01)$, followed by $T_{\text {mean }}\left(R^{2}=0.48, p<0.05\right)$ in the second period (19942010). PET $\mathrm{PT}_{\mathrm{PT}}$ is driven by $S\left(R^{2}=0.72, p<0.01\right)$ during 1981-93, while RH $\left(R^{2}=0.49, p<0.05\right)$ leads to the increasing PET $_{\mathrm{PT}}$ during 1994-2010. As
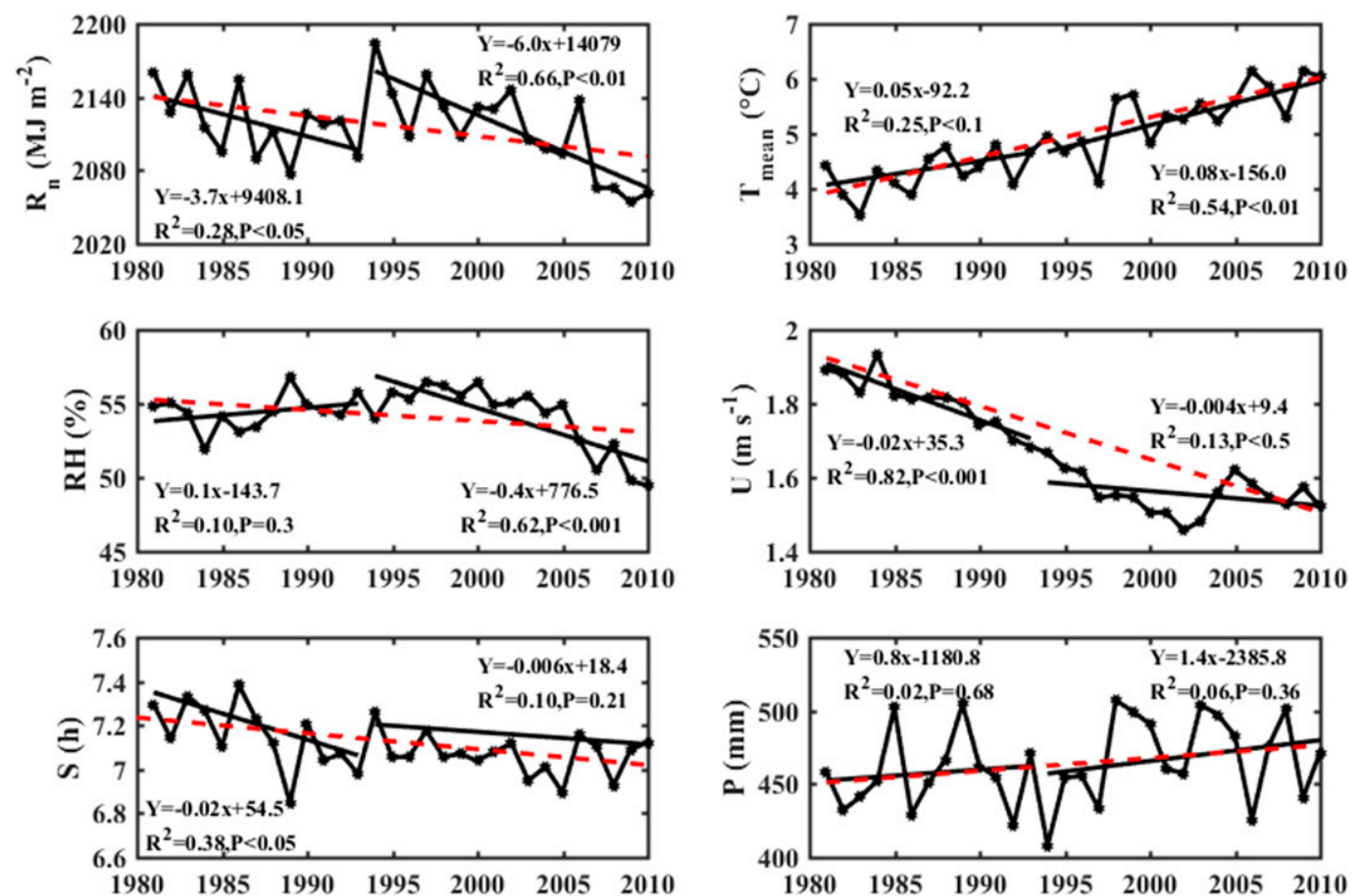

Figure 8. The temporal patterns of annual-mean values of the meteorological factors affecting PET on the Tibetan Plateau during 1981 to 2010 (solar radiation $R_{n}$, mean temperature $I_{\text {mean }}$, relative humidity $\mathrm{RH}$, wind speed $U$, and sunshine duration $S$ ). 


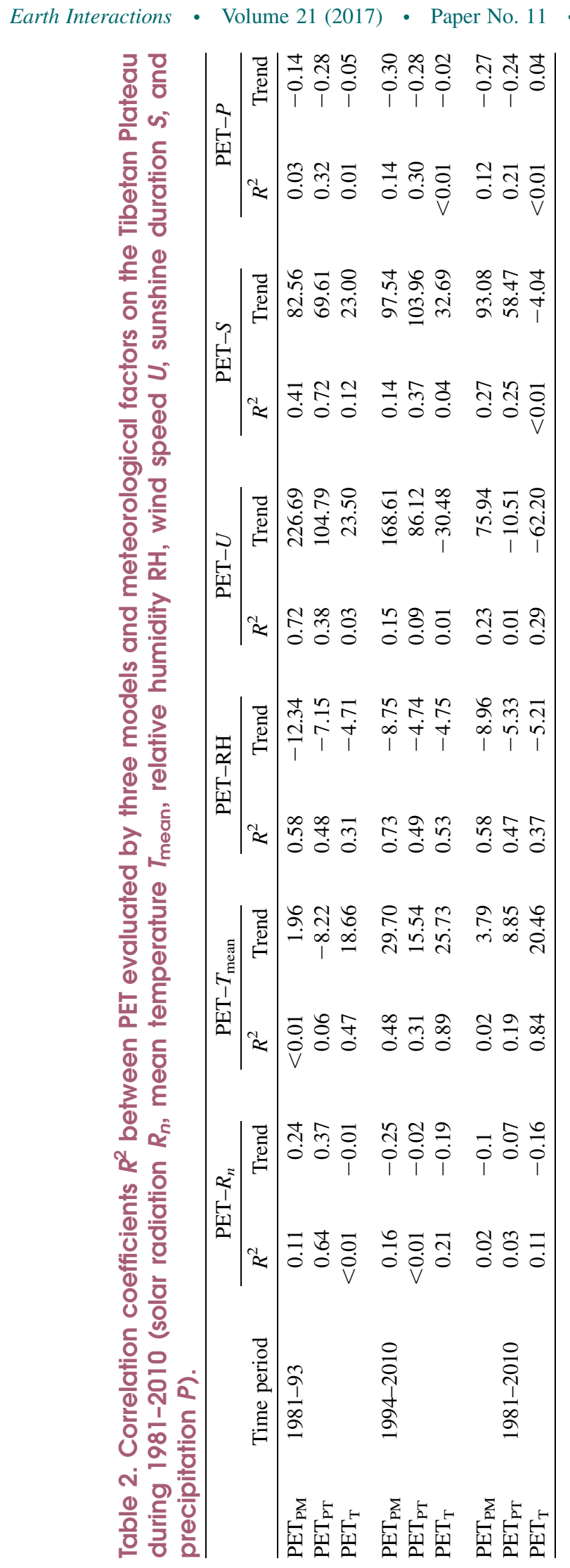


Earth Interactions - Volume 21 (2017) • Paper No. 11 • Page 16

opposed to the other two models, the increasing $T_{\text {mean }}$ dominates the increasing PET $_{\mathrm{T}}$ in two stages $\left(R^{2}=0.47\right.$ and 0.89 , respectively, $\left.p<0.01\right)$.

\section{Discussion}

\subsection{From daily to annual scale}

In this study, we used meteorological data to estimate PET with different models and investigated PET variations on daily, seasonal, and annual scales. Although the three models demonstrated similar PET values on average annual and daily scales, the spatial distribution and interannual trends of estimated PET revealed considerable inconsistence among different parts of the Tibetan Plateau.

For both mean daily and annual scales, the lowest PET $_{\mathrm{T}}$ value of the three models was similar to previous PET intercomparison studies. For example, Hulme et al. (1996) showed that the value of $\mathrm{PET}_{\mathrm{T}}$ in Africa was generally lower than $\mathrm{PET}_{\mathrm{PM}}$ and PET $_{\mathrm{PT}}$. Similarly, Chen et al. (2006) demonstrated that values from PET $_{\mathrm{T}}$ were lower

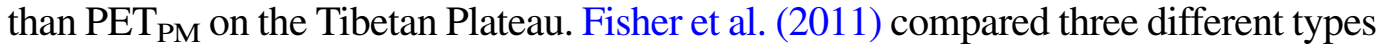
of PET models for 11 land-cover types at global scale, showing that $\mathrm{PET}_{\mathrm{T}}$ estimated 20\%-30\% less than PET $_{\mathrm{PT}}$ and PET $_{\mathrm{PW}}$. Furthermore, Lu et al. (2005) showed that $\mathrm{PET}_{\mathrm{T}}$ for the United States was the lowest among six PET models.

In addition, the $\mathrm{PET}_{\mathrm{T}}$ did not agree well with the other two models either in regional variations (Figure 2) or among different land-cover types (Figure 7). The mean annual bias indicated that $\mathrm{PET}_{\mathrm{T}}$ overestimated PET over monsoon-affected areas (forests in the southeastern plateau) where climate was relatively humid, whereas it gave an underestimation over arid areas in the west of the Tibetan Plateau. The reason for this was that the Thornthwaite model assumed vegetation cover and depended heavily on the accuracy of temperature without considering net radiation function. For instance, erroneously low temperature can lead to excessively low PET in the Thornthwaite model.

Our results showed $\mathrm{PET}_{\mathrm{PT}}$ agreed well with $\mathrm{PET}_{\mathrm{PM}}$ not only for temporal variations (at both mean daily and annual scales) but also for spatial variations except

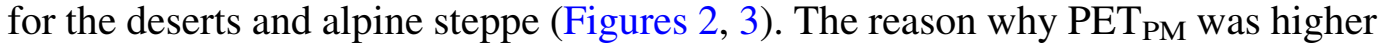
than $\mathrm{PET}_{\mathrm{PT}}$ in these regions (low $R_{n}$ and relatively high VPD) was that the VPDdriven Penman-Monteith model gave higher PET than that from the PriestleyTaylor model without considering VPD.

Overall, much care must be taken when selecting the appropriate model for estimating PET for a particular region. Generally, a temperature-based model should be avoided if data are available to run the other models or if the vegetation cover is low. If only data for a temperature-based model are available, the authors should consider the calibration for the results according to our results on daily and annual scales. In addition, although the radiation-based model showed the closest results with combination model, it should be noted that the combination model will probably give lower PET estimates in alpine meadow and alpine cushion vegetation on the Tibetan Plateau.

\subsection{Impact of meteorological factors}

Differences in the interannual variation of PET are regulated by different modeldominated meteorological factors; $T_{\text {mean }}$, as a surrogate for atmospheric demand, is a 
critical meteorological driver for the temperature-based models (Fisher et al. 2011). It can be inferred from the Thornthwaite model that the increase in $\mathrm{PET}_{\mathrm{T}}$ on the plateau was mainly due to the rising $T_{\text {mean }}$ from 1981 to 2010 . This increasing trend in $\mathrm{PET}_{\mathrm{T}}$ was more obvious after 1994 when $T_{\text {mean }}$ started to increase sharply (Figure 8).

In our study, we confirmed the general pattern of decreasing trends in $\mathrm{PET}_{\mathrm{PM}}$ across the Tibetan Plateau as identified by previous studies (Chen et al. 2006; Zhang et al. 2009; Wang et al. 2013; Liang et al. 2013; Yin et al. 2010; Figure 4a). Similar with previous studies, the decreasing wind speed, which was caused by the decrease in Asian monsoon strength, was the primary factor for the interannual pattern of PET $_{\mathrm{PM}}$ before 1993 (Yin et al. 2010; Wang et al. 2013). Some research pointed out that urbanization (e.g., tall buildings) may cause the wind speed reduction. However, the anthropogenic impacts on the plateau are far less serious than most regions of the world, and the impact of urbanization on wind speed might be negligible (Q. Liu et al. 2010). During the past two decades, the decreasing RH and increasing air temperature, which offset the negative effects of wind speed, resulted in increasing $\mathrm{PET}_{\mathrm{PM}}$. This result can be explained by the fact that the increasing $T_{\text {mean }}$ caused a simultaneous increase in both VPD and outward longwave radiation. The increase in VPD accelerated the water transfer, while the increase in longwave radiation decreased $R_{n}$ (Figure 8). $\mathrm{PET}_{\mathrm{PM}}$ increased when VPD-induced increase in PET $_{\mathrm{PM}}$ was higher than the amount of decrease in PET $_{\mathrm{PM}}$ caused by the increase of longwave radiation under low air temperature conditions.

Our results demonstrated that the decreasing $S$ followed by $R_{n}$ (calculated by $S$ ) were the dominant factors to drive the interannual PET ${ }_{\mathrm{PT}}$ trend before 1993. However, after 1994, the contributions of both $S$ and $R_{n}$ were less than those of RH (Table 2), which demonstrated that PET $_{\mathrm{PT}}$ was thermodynamic limited before 1993 and turned to be water limited after 1994. It should be noted that, as opposed to the interannual pattern of $\mathrm{PET}_{\mathrm{T}}$, the mean annual $\mathrm{PET}_{\mathrm{PT}}$ and $\mathrm{PET}_{\mathrm{PM}}$ experienced a concave pattern with decreases from 1980 to 1993, and this reversed after 1994. Previous studies also documented that the 1990s marked a transition period in which the trend in PET showed an increasing pattern (Wang et al. 2013; Zhang et al. 2009). We also compared our results with the pan evaporation $\mathrm{ET}_{\text {pan }}$ measured by previous studies (the meteorological records used in our study did not include the $\mathrm{ET}_{\mathrm{pan}}$ ) and found that $\mathrm{ET}_{\text {pan }}$ have similar patterns. For example, M. Liu et al. (2010) demonstrated that the nationwide average ET $_{\text {pan }}$ data first decreased during 1960-92 and then increased after 1992 because of seriously rising air temperature. Similar results were also reported by Wang et al. (2013).

The magnitude of interannual PET variations will differ because of different meteorological drivers. Disparate combinations of meteorological factors may induce diverse PET trends under the influence of the same meteorological variables. Generally, if only data for a temperature-based model are available for the interannual PET estimation, it is necessary to consider the changing points identified from our analyses.

\section{Conclusions}

In this study, we compared three PET models, including a radiation-based model (Priestley-Taylor model), a temperature-based model (Thornthwaite model), and a combination model (Penman-Monteith model), based on daily data from 80 meteorological stations on the Tibetan Plateau from 1981 to 2010. The results showed 
Earth Interactions - Volume 21 (2017) • Paper No. 11 • Page 18

that the Penman-Monteith and Priestley-Taylor models demonstrated similar estimations at annual and daily scales. The Thornthwaite estimates were lower than the other two models. Regionally, PET estimated by Penman-Monteith and Priestley-Taylor models showed similar spatial patterns with a declining gradient from west to east. PET estimated by Thornthwaite showed a significant increasing trend from 1981 to 2010, but the other two models revealed transitions around 1993. The differences in model structures and their dominant variables were the major reasons explaining the differences among their interannual PET variations. Overall, it is important to understand that most PET models have been developed for use in specific studies and that they were constructed to be most appropriate for use in the climates of the locations where they were developed. Our study suggests that careful consideration and verification are needed before applying a PET model in hydrological and ecological studies.

Acknowledgments. This study was supported by the Natural Science Foundation of Fujian Province, China (2017J01069); the National Natural Science Foundation of China (31600368); the Fundamental Research Funds for the Central Universities of China (20720160109); the National Key Research and Development Program of China (2017YFC0506100); the NASA Land-Cover and Land-Use Change Program (NASANNX09AI26G); and the NSF Division of Information and Intelligent Systems (NSF1028291).

\section{Appendix A: A Full Description of the Penman-Monteith Model}

The parameters of Equation (1) were determined as follows below.

Net radiation $R_{n}$ was computed by equations recommended by Yin et al. (2008), which was calibrated by observed solar radiation of 80 meteorological stations over China and measurements of net longwave radiation on the Tibetan Plateau:

$$
\begin{aligned}
R_{n}= & 0.77 \times\left(0.20+0.79 \frac{n}{N}\right) R_{\mathrm{so}}-\sigma\left(\frac{T_{\max , k}^{4}+T_{\min , k}^{4}}{2}\right) \\
& \times\left(0.56-0.25 \sqrt{e_{a}}\right)\left(0.1+0.9 \frac{n}{N}\right),
\end{aligned}
$$

where $\sigma$ is the Stefan-Boltzmann constant $\left(4.903 \times 10^{-9} \mathrm{MJ} \mathrm{K}^{-4} \mathrm{~m}^{-2}\right.$ day $\left.^{-1}\right)$; $T_{\max , k}$ and $T_{\min , k}$ are the maximum and minimum temperatures in kelvins, respectively; $s$ is actual sunshine duration (h); $S$ is potential sunshine hours; and $R_{\text {so }}$ is clear-sky solar radiation. The calculation of $R_{\text {so }}$ followed the procedure outlined in Allen et al. (1998).

Soil heat flux $G$ was calculated using mean temperature with a simple formula:

$$
G=0.14\left(T_{\text {mean }, i}-T_{\text {mean }, i-1}\right),
$$

where $T_{\text {mean, } i}$ is the mean temperature of the $i$ day, and $T_{\text {mean, } i-1}$ is the mean temperature of the previous day. 
Earth Interactions • Volume 21 (2017) • Paper No. 11 • Page 19

Table B1. The mean and square deviation (SD) of PET values estimated by three models during 1981-2010.

\begin{tabular}{|c|c|c|c|}
\hline Year & $\operatorname{PET}_{\mathrm{PM}}(\mathrm{mm})$ & $\mathrm{PET}_{\mathrm{PT}}(\mathrm{mm})$ & $\mathrm{PET}_{\mathrm{T}}(\mathrm{mm})$ \\
\hline 1981 & 728.1 & 701.4 & 667.6 \\
\hline 1982 & 706.2 & 689.3 & 649.1 \\
\hline 1983 & 702.9 & 697.9 & 647.6 \\
\hline 1984 & 749.7 & 701.1 & 672.0 \\
\hline 1985 & 707.3 & 680.8 & 653.3 \\
\hline 1986 & 714.6 & 704.5 & 660.7 \\
\hline 1987 & 716.4 & 683.7 & 676.0 \\
\hline 1988 & 717.6 & 696.1 & 671.7 \\
\hline 1989 & 685.1 & 667.0 & 642.8 \\
\hline 1990 & 694.3 & 684.6 & 664.3 \\
\hline 1991 & 703.9 & 689.7 & 667.4 \\
\hline 1992 & 684.1 & 683.9 & 658.0 \\
\hline 1993 & 677.0 & 665.4 & 666.8 \\
\hline 1994 & 717.7 & 720.7 & 685.5 \\
\hline 1995 & 690.4 & 699.5 & 664.8 \\
\hline 1996 & 685.9 & 680.3 & 672.1 \\
\hline 1997 & 663.7 & 683.8 & 653.2 \\
\hline 1998 & 693.0 & 696.4 & 691.5 \\
\hline 1999 & 692.6 & 692.7 & 695.2 \\
\hline 2000 & 662.4 & 678.1 & 670.1 \\
\hline 2001 & 680.2 & 687.4 & 685.1 \\
\hline 2002 & 678.7 & 698.3 & 687.2 \\
\hline 2003 & 669.5 & 680.6 & 685.8 \\
\hline 2004 & 688.5 & 687.4 & 677.7 \\
\hline 2005 & 689.7 & 686.1 & 679.5 \\
\hline 2006 & 730.2 & 727.1 & 708.7 \\
\hline 2007 & 725.5 & 712.8 & 704.5 \\
\hline 2008 & 694.4 & 691.1 & 680.5 \\
\hline 2009 & 734.9 & 713.6 & 709.6 \\
\hline 2010 & 731.1 & 716.5 & 705.4 \\
\hline Mean $\pm \mathrm{SD}$ & $700.5 \pm 22.3$ & $693.3 \pm 14.7$ & $675.1 \pm 18.3$ \\
\hline
\end{tabular}

The parameters $\Delta$ and $\gamma$ were computed as

$$
\begin{aligned}
& \Delta=\frac{4098\left[0.6108 \exp \left(\frac{17.27 T_{\text {mean }}}{T_{\text {mean }}+237.3}\right)\right]}{\left(T_{\text {mean }}+237.3\right)^{2}} \text { and } \\
& \gamma=\frac{C_{p} P}{\varepsilon \lambda}=0.000665 \times P \\
& P=101.3\left(\frac{293-0.0065 h}{293}\right)^{5.26} \\
& \lambda=2.501-0.002361 \times T_{\text {mean }},
\end{aligned}
$$

where $C_{p}$ is the specific heat of moist air $\left(\mathrm{kJ} \mathrm{kg}^{-1}{ }^{\circ} \mathrm{C}^{-1}\right), P$ is atmospheric pressure $(\mathrm{kPa}), \lambda$ is the latent heat of vaporization $\left(\mathrm{MJ} \mathrm{kg}^{-1}\right)$, and $h$ is altitude $(\mathrm{m})$. 


\section{Earth Interactions - Volume 21 (2017) • Paper No. 11 • Page 20}

To convert wind speed data obtained at $10 \mathrm{~m}$ to the standard height of $2 \mathrm{~m}$,

$$
U_{2}=0.75 \times U_{10}
$$

The $e_{s}$ and $e_{a}$ were estimated with mean daily relative humidity $\mathrm{RH}_{\text {mean }}$ and temperature:

$$
\begin{aligned}
e_{s} & =\frac{e^{0}\left(T_{\max }\right)+e^{0}\left(T_{\min }\right)}{2} \\
e_{a} & =\frac{\mathrm{RH}_{\text {mean }}}{100} e_{s} \\
e^{0}(T) & =0.6108 \exp \left(\frac{17.27 T}{T+237.3}\right) .
\end{aligned}
$$

\section{Appendix B: The Mean and Square Deviation of PET Values Estimated by Three Models}

Potential evapotranspiration values are given by Penman-Monteith, PriestleyTaylor, and Thornthwaite models in Table B1.

\section{References}

Allen, R. G., L. S. Pereira, D. Raes, and M. Smith, 1998: Crop evapotranspiration: Guidelines for computing crop water requirements. FAO Irrigation and Drainage Paper 56, http://www.fao. org/docrep/X0490E/X0490E00.htm.

Camargo, A. P., F. R. Marin, P. C. Sentelhas, and A. G. Picini, 1999: Adjust of the Thornthwaite's method to estimate the potential evapotranspiration for arid and super humid climates, based on daily temperature amplitude, I (in Portuguese with English summary). Agrometeorologica, 7, 251-257.

Chen, S., Y. Liu, and A. Thomas, 2006: Climatic change on the Tibetan Plateau: Potential evapotranspiration trends from 1961-2000. Climatic Change, 76, 291-319, https://doi.org/ 10.1007/s10584-006-9080-z.

Currie, D. J., 1991: Energy and large-scale patterns of animal and plant-species richness. Amer. Nat., 137, 27-49, https://doi.org/10.1086/285144.

Douglas, E. M., J. M. Jacobs, D. M. Sumner, and R. L. Ray, 2009: A comparison of models for estimating potential evapotranspiration for Florida land cover types. J. Hydrol., 373, 366376, https://doi.org/10.1016/j.jhydrol.2009.04.029.

Er-Raki, S., A. Chehbouni, S. Khabba, V. Simonneaux, L. Jarlan, A. Ouldbba, J. C. Rodriguez, and R. Allen, 2010: Assessment of reference evapotranspiration methods in semi-arid regions: Can weather forest data be used as alternate of ground meteorological parameters? J. Arid Environ., 74, 1587-1596, https://doi.org/10.1016/j.jaridenv.2010.07.002.

Fisher, J. B., T. A. DeBiase, Y. Qi, M. Xu, and A. H. Goldstein, 2005: Evapotranspiration models compared on a Sierra Nevada forest ecosystem. Environ. Modell. Software, 20, 783-796, https://doi.org/10.1016/j.envsoft.2004.04.009.

— - R. J. Whittaker, and Y. Malhi, 2011: ET come home: Potential evapotranspiration in geographical ecology. Global Ecol. Biogeogr., 20, 1-18, https://doi.org/10.1111/ j.1466-8238.2010.00578.x.

Hulme, M., D. Conway, A. Joyce, and H. Mulenga, 1996: A 1961-90 climatology for Africa south of the equator and a comparison of potential evapotranspiration estimates. S. Afr. J. Sci., 92, 334-343. 
Earth Interactions - Volume 21 (2017) • Paper No. 11 • Page 21

Kendall, M. G., 1975: Rank Correlation Methods. London, 202 pp.

Li, J., and X. Fang, 1999: Uplift of the Tibet Plateau and environmental changes. Chin. Sci. Bull., 44, 2117-2124, https://doi.org/10.1007/BF03182692.

Liang, L., L. Li, C. Liu, and L. Cuo, 2013: Climate change in the Tibetan Plateau Three Rivers Source region: 1960-2009. Int. J. Climatol., 33, 2900-2916, https://doi.org/10.1002/joc.3642.

Liu, M., Y. J. Shen, Y. Zeng, and C. M. Liu, 2010: Trend in pan evaporation and its attribution over the past 50 years in China. J. Geogr. Sci., 20, 557-568, https://doi.org/10.1007/s11442-010-0557-3.

Liu, Q., Z. F. Yang, B. S. Cui, and T. Sun, 2010: The temporal trends of reference evapotranspiration and its sensitivity to key meteorological variables in the Yellow River basin, China. Hydrol. Processes, 24, 2171-2181, https://doi.org/10.1002/hyp.7649.

Lu, G. Y., and D. W. Wong, 2008: An adaptive inverse-distance weighting spatial interpolation technique. Comput. Geosci., 34, 1044-1055, https://doi.org/10.1016/j.cageo.2007.07.010.

Lu, J., G. Sun, S. G. McNulty, and D. M. Amatya, 2005: A comparison of six potential evapotranspiration methods for regional use in the southeastern United States. J. Amer. Water. Resour. Assoc., 41, 621-633, https://doi.org/10.1111/j.1752-1688.2005.tb03759.x.

Mann, H. B., 1945: Nonparametric tests against trend. Econometrica, 13, 245-259, https://doi.org/ $10.2307 / 1907187$.

McNaughton, K. G., and T. A. Black, 1973: A study of evapotranspiration from a Douglas fir forest using the energy balance approach. Water Resour. Res., 9, 1579-1590, https://doi.org/ 10.1029/WR009i006p01579.

Monteith, J. L., 1965: Evaporation and the environment. Symp. Soc. Explor. Biol., 19, 205-234.

Penman, H. L., 1948: Natural evaporation from open water, bare soil and grass. Proc. Roy. Soc. London, A193, 120-146, https://doi.org/10.1098/rspa.1948.0037.

Priestley, C. H. B., and R. J. Taylor, 1972: On the assessment of the surface heat flux and evaporation using large-scale parameters. Mon. Wea. Rev., 100, 81-92, https://doi.org/10.1175/ 1520-0493(1972) $100<0081$ :OTAOSH $>2.3 . \mathrm{CO} ; 2$.

Sentelhas, P. C., T. J. Gillespie, and E. A. Santos, 2010: Evaluation of FAO Penman-Monteith and alternative methods for estimating reference evapotranspiration with missing data in southern Ontario, Canada. Agric. Water Manage., 97, 635-644, https://doi.org/10.1016/ j.agwat.2009.12.001.

Shao, Q. X., and N. A. Campbell, 2002: Modelling trends in groundwater levels by segmented regression with constraints. Aust. N. Z. J. Stat., 44, 129-141, https://doi.org/10.1111/ 1467-842X.00216.

— Z. Z. Li, and Z. X. Xu, 2010: Trend detection in hydrological time series by segment regression with application to Shiyang River basin. Stochastic Environ. Res. Risk Assess., 24, 221-233, https://doi.org/10.1007/s00477-009-0312-4.

Sneyers, R., 1990: On the Statistical Analysis of Series of Observation. World Meteorological Society, $192 \mathrm{pp}$.

Song, L. L., Q. Zhuang, Y. Yin, X. Zhu, and S. Wu, 2017: Spatio-temporal dynamics of evapotranspiration on the Tibetan Plateau from 2000 to 2010. Environ. Res. Lett., 12, 014011, https://doi.org/10.1088/1748-9326/aa527d.

Steiner, J. L., T. A. Howell, and A. D. Schneider, 1991: Lysimetric evaluation of daily potential evaporation models for grain sorghum. Agron. J., 83, 240-247, https://doi.org/10.2134/ agronj1991.00021962008300010055x.

Thornthwaite, C. W., 1948: An approach toward a rational classification of climate. Geogr. Rev., 38, 55-94, https://doi.org/10.2307/210739.

Wang, W., and Coauthors, 2013: Changes in reference evapotranspiration across the Tibetan Plateau: Observations and future projections based on statistical downscaling. J. Geophys. Res. Atmos., 118, 4049-4068, https://doi.org/10.1002/jgrd.50393.

Xu, C. Y., and V. P. Singh, 2000: Evaluation and generalization of radiation-based methods for calculating evaporation. Hydrol. Processes, 14, 339-349, https://doi.org/10.1002/ (SICI) 1099-1085(20000215)14:2<339::AID-HYP928>3.0.CO;2-O. 
Earth Interactions - Volume 21 (2017) • Paper No. 11 • Page 22

— and _ 2001: Evaluation and generalization of temperature-based methods for calculating evaporation. Hydrol. Processes, 15, 305-319, https://doi.org/10.1002/hyp.119.

Yin, Y., S. Wu, D. Zheng, and Q. Yang, 2008: Radiation calibration FAO56 Penman-Monteith model to estimate reference crop evapotranspiration in China. Agr. Water Manage., 95, 7784, https://doi.org/10.1016/j.agwat.2007.09.002.

— — _ - and E. Dai, 2010: Determining factors in potential evapotranspiration changes over China in the period 1971-2008. Chin. Sci. Bull., 55, 3329-3337, https://doi.org/10.1007/ s11434-010-3289-y.

Zhang, X., Y. Ren, Z. Y. Yin, Z. Lin, and D. Zheng, 2009: Spatial and temporal variation patterns of reference evapotranspiration across the Qinghai-Tibetan Plateau during 1971-2004. J. Geophys. Res., 114, D15105, https://doi.org/10.1029/2009JD011753.

Earth Interactions is published jointly by the American Meteorological Society, the American Geophysical Union, and the Association of American Geographers. For information regarding reuse of this content and general copyright information, consult the AMS Copyright Policy (www.ametsoc.org/PUBSReuseLicenses). 